\title{
Effect of Chloride lons on the Reaction of Diphenylamine with DNA ${ }^{1}$
}

\author{
W. WILBUR ACKERMANN, F. SOKOL, ${ }^{2}$ AND \\ ALLEN J. BRANDAU, JR. ${ }^{3}$ \\ From the Department of Epidemiology and Virus Laboratory, \\ School of Public Health, University of Michigan, \\ Ann Arbor, Michigan
}

Received March 31, 1964

It is known that diphenylamine under conditions of the Dische test may react with certain sugars when present at high concentrations (1). Further, it has been long recognized that a high mineral acid content in the reagent enhances the reaction with hexoses $(2,3)$. This is the basis of a method for fructose and inulin determination $(2,4)$. However, for analytical determination of DNA, the reagent is usually applied to partially purified material (acid precipitated) from which interfering substances are removed. Currently less severe methods of purification are being employed to isolate DNA in polymeric native forms using $\mathrm{CsCl}$ density gradients, sucrose gradient centrifugation, or column chromatography with salt elution. The preparation is likely to be contaminated with high molecular weight polymeric sugars (5) as well as with these apparently innocuous suspending media. These, when present in the standard Dische test, might be expectcd to condition the reagent to act as a hexose reagent (2), thus reducing the sensitivity of the DNA determination while producing a falsely high positive reading. The following observations concern the quantitative and qualitative effects of halogen ions in the standard Dische reaction.

\section{MATERIALS AND METHODS}

Diphenylamine (Distillation Products Industries, Rochester, New York) was freshly recrystallized twice from 70\% ethanol.

Acetic acid (E. I. du Pont de Nemours \& Co., Wilmington, Del.) of high quality is necessary for a satisfactory reagent blank.

${ }^{1}$ These studies were supported in part by The National Foundation.

${ }^{2}$ Permanent address: Institute of Virology, Czechoslovak Academy of Sciences, Bratislava, Czechoslovakia. Supported in part by a stipend from U. S. Public Health Trainee Grant No. 5T1 AI 60-05.

${ }^{3}$ Recipient of a stipend from U. S. Public Health Trainee Grant No. 2G-6(5). 
Procedure Using Dische Reagent: $1 \mathrm{gm}$ diphenylamine was dissolved in $100 \mathrm{ml}$ glacial acetic acid and $2.75 \mathrm{ml}$ concentrated $\mathrm{H}_{2} \mathrm{SO}_{4}$ added; $1 \mathrm{ml}$ of sample was added to $2 \mathrm{ml}$ reagent and unless specified to the contrary heated at $100^{\circ} \mathrm{C}$ for $10 \mathrm{~min}$. The optical density was read at $595 \mathrm{~m} \mu$ as described by Dische (3) when DNA was employed as the sample.

Sugars and other substances were dried in a vacuum desiccator at $20^{\circ} \mathrm{C}$ before weighing and dissolving in distilled water: D-fructose and glycogen, oyster (Distillation Products Industries, Rochester, New York) ; D-mannose and inulin (Nutritional Biochemical Corporation, Cleveland, Ohio) ; D-galactose (Mann Research Laboratories, New York, New York); D-ribose (Schwartz Laboratories, Incorporated, Mount Vernon, New York); D-glucose (Corn Products Refining Company, New York, New York); dextrin (Baker and Adamson of Allied Chemical, New York, New York); DNA, sperm (National Biochemical Company, Chicago, Illinois) ; 5-hydroxymethylfurfural (Columbia Organic Chemical Company, Columbia, South Carolina); RNA, mouse liver, prepared in this laboratory.

\section{EXPERIMENTAL AND RESULTS}

Effect of Chlorides on Sensitivity of the Dische Test for DNA. Solutions were prepared containing $390 \mu \mathrm{g}$ DNA $/ \mathrm{ml}$ in aqueous solutions of graded concentrations of $\mathrm{CsCl}$ or $\mathrm{NaCl}$. These preparations were assayed for DNA with the Dische method. The optical density was determined at $595 \mathrm{~m}_{\mu}$ after the development of color by heating at $100^{\circ} \mathrm{C}$ for $10 \mathrm{~min}$. In Fig. 1 the optical density is plotted as a function of the molarity of the

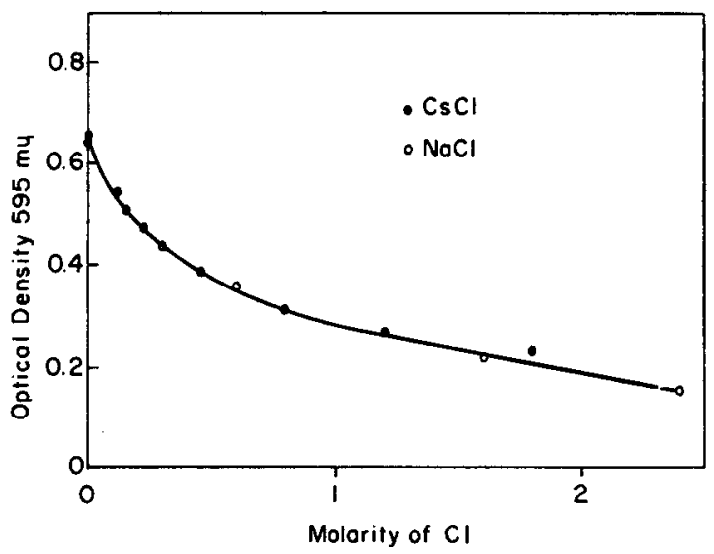

FIG. 1. Effect of chloride ion concentration on reaction of DNA with Dische diphenylamine reagent. Concentration of DNA constant throughout at $390 \mu \mathrm{g} / \mathrm{ml}$ $\left(100^{\circ} \mathrm{C}, 10 \mathrm{~min}\right)$. 
chloride ion. It will be noted that concentrations as low as $0.1 M$ chloride ion significantly depress the development of color while at $2 M$ the reduction is over $60 \%$. Further, on a molar basis the two salts are entirely equivalent. A similar effect can be obtained with hydrogen chloride, magnesium chloride, or potassium bromide and it is concluded that the halogen ion rather than the cation affects the interference. Iodides and fluorides can not be evaluated readily in this system since the former is oxidized to free iodine and the latter is sparingly soluble.

Basis of the Chloride Effect upon the Dische Test for DNA. The basis for the reduction in sensitivity of the Dische test for DNA produced by chloride ion is apparent from an inspection of the absorption spectrum of the reaction mixture. Chloride ion, at an optimum concentration, was added to the diphenylamine reagent in glacial acetic acid in the form of hydrogen chloride. The sulfuric acid was found not to be influential and was omitted. The modified reagent was allowed to react $40 \mathrm{~min}$ at $100^{\circ} \mathrm{C}$ under optimal conditions of temperature and time with DNA dissolved in distilled water. In Fig. 2, optical density of the reaction products

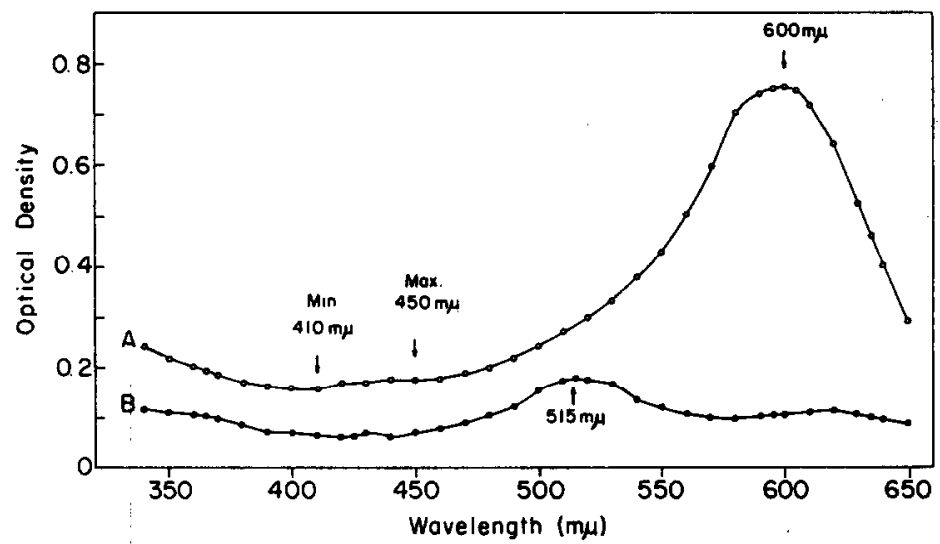

Fig. 2. (A) Spectrum of product of reaction between DNA $(489 \mu \mathrm{g} / \mathrm{ml})$ and Dische reagent $\left(100^{\circ} \mathrm{C}, 10 \mathrm{~min}\right)$. (B) Spectrum of product of reaction between DNA $(974 \mu \mathrm{g} / \mathrm{ml})$ and $\mathrm{HCl}$-diphenylamine reagent $\left(100^{\circ} \mathrm{C}, 40 \mathrm{~min}\right)$.

measured at various wavelengths in the visible region is recorded for DNA treated with the standard Dische reagent and the HCl-diphenylamine modification. Under the influence of chloride the maximum absorption is shifted from 600 to $515 \mathrm{~m}_{\mu}$. The absorption at $600 \mathrm{~m} \mu$ is nearly eliminated by the chloride and the intensity at 515 is only $12 \%$ of that at $600 \mathrm{~m}_{\mu}$ produced under standard conditions. When absorption at the maximum of $515 \mathrm{~m} \mu$ was examined over a range of concentrations of 
DNA from 100 to $1000 \mu \mathrm{g} / \mathrm{ml}$, the optical density deviated slightly from that predicted by Beer's law.

Effect of Chloride Ion on Specificity of the Dische Test for DNA. Preparations of DNA obtained by phenol extraction of HeLa cells or mouse livers (purified by alcohol precipitation and equilibrium density gradient centrifugation in $\mathrm{CsCl}$ ) and diluted in saline give a falsely high determination, compared to standard preparations, when tested with the Dische reagent. Examination of the absorption curve of the reaction product showed maxima at 635,520 , and $360 \mathrm{~m} \mu$. The curve was identical with that obtained with fructose in the $\mathrm{HCl}$-diphenylamine reaction (2). Further, mere addition of chloride salts to a sample of fructose (which is ordinarily not reactive) was found to produce an intensifying effect when the standard Dische test is employed with it. Later the purified DNA was shown to contain appreciable high molecular weight polyglucose, which has the same buoyant density as DNA (5). The form of the absorption curve for fructose obtained under these conditions is identical in all details with that obtained from the reaction in the presence of chloride $(1 M)$ of the six-carbon sugars, D-mannose, D-glucose, D-galactose, and the polymers inulin, glycogen, and dextran. The molar absorptivity, however, varies (Table 1). This characteristic curve is obtained

TABLE 1

Wavelength (M $\mu$ ) of Maxima and Minima, Optical Density, and Molar Absorptivity of Hexoses, ${ }^{a}$ and Their Polymers after Reaction With the HCl-Diphenylamine Reagent

\begin{tabular}{|c|c|c|c|c|c|c|c|c|c|}
\hline \multirow{2}{*}{$\begin{array}{l}\text { Compound } \\
\text { Fructose }\end{array}$} & \multicolumn{2}{|c|}{ Max. OD } & \multicolumn{2}{|c|}{ Min. OD } & \multicolumn{2}{|c|}{ Max. OD } & \multicolumn{2}{|c|}{ Max. OD } & \multirow{2}{*}{$\frac{E_{\cos } \times 10^{8}}{5.65}$} \\
\hline & 635 & 0.785 & 560 & 0.377 & 520 & 0.563 & 365 & 0.153 & \\
\hline Inulin & 634 & 0.767 & 561 & 0.375 & 520 & 0.564 & 366 & 0.155 & $5.60^{b}$ \\
\hline Glucose & 635 & 0.180 & 560 & 0.083 & 522 & 0.127 & 365 & 0.043 & 1.18 \\
\hline Glycogen & 634 & 0.163 & 558 & 0.075 & 520 & 0.116 & 366 & 0.040 & $1.16^{b}$ \\
\hline Dextran & 635 & 0.174 & 562 & 0.085 & 520 & 0.128 & 365 & 0.045 & $1.17^{b}$ \\
\hline Mannose & 635 & 0.162 & 563 & 0.084 & 521 & 0.123 & 367 & 0.045 & 1.16 \\
\hline Galactose & 635 & 0.055 & 563 & 0.029 & 521 & 0.043 & 367 & 0.015 & 0.396 \\
\hline
\end{tabular}

a Concentration of sugars and polysaccharides $25 \mu \mathrm{g} / \mathrm{ml}$; optical path $1 \mathrm{~cm}$.

${ }^{b}$ Based upon the hexose content.

with 5 -hydroxymethylfurfural. If heated $40 \mathrm{~min}$ but not 10 , it also reacts in the standard Dische test without chloride ion. Such six-carbon derivatives as glucosamine, galactosamine, or mannitol give no color reaction while a red color is produced with 2-deoxyglucose. Ribose and ribonucleic acid are particularly interesting in that their absorption curves, while distinct from hexoses, are identical to each other but differ in the molar 
absorptivity calculated from the ribose content. The optical density at the maximum, $365 \mathrm{~m}_{\mu}$, was 0.841 for a concentration of $1000 \mu \mathrm{g} \mathrm{RNA} / \mathrm{ml}$ and 0.291 for $100 \mu \mathrm{g}$ ribose $/ \mathrm{ml}$.

Kinetic Differentiation of the Glucose and Fructose Reactions. The difference in the chromogenic potential of fructose and glucose in the $\mathrm{HCl}$-diphenylamine reaction, indicated by the marked difference in the molar absorptivity of the reaction products, is partially a consequence of the kinetics of reaction. Equal concentrations $(25 \mu \mathrm{g} / \mathrm{ml})$ of glucose and fructose were allowed to react at $100^{\circ} \mathrm{C}$ with the $\mathrm{HCl}$-diphenylamine reagent and at various intervals the optical density at $635 \mathrm{~m} \mu$ was determined. The data are plotted in Fig. 3. It is readily apparent from the

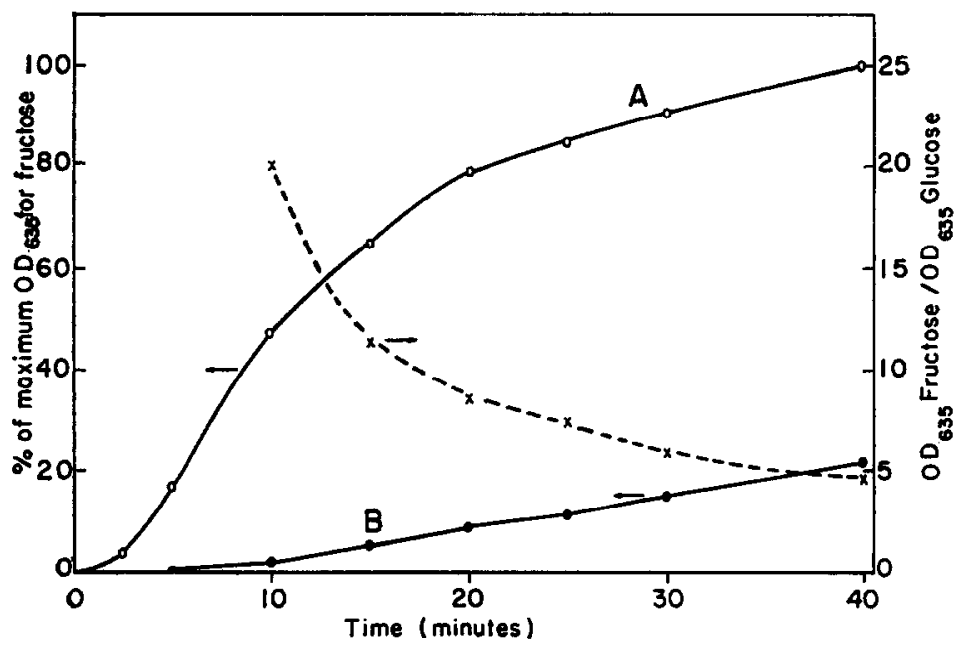

Fig. 3. Kinetics of reaction of fructose (A) and glucose (B) with $\mathrm{HCl}$-diphenylamine reagent. The optical density at the maximum 635 is plotted as function of time for each point expressed as percentage of maximum optical density developed by fructose at $40 \mathrm{~min}$. The broken line is the ratio of optical density of fructose to optical density of glucose.

slope of the curves at any point that the rate of development of color throughout the 40-min period is greater with fructose and significantly so in the initial period. The more rapid reaction of fructose is also reflected in the relative rates of reaction of the corresponding polymers inulin and glycogen.

\section{DISCUSSION}

The mechanism of the chloride effect in the diphenylamine reaction, described in the experimental section, remains obscure. It has been 
observed that the ion must be present with the sugar and reagent at the time of heating and would seem to affect the nature of the colored reaction product rather than alter the ability of the usual product to absorb light energy.

The reactivity of 5-hydroxymethylfurfural in the presence or absence of halogen ions suggests it is an intermediate in the formation of the colored product from fructose. The primary role of chloride ion is to effect the conversion of fructose to furfural, which apparently is quantitative, since the molar absorptivity of fructose and the furfural are identical when the $\mathrm{HCl}$-diphenylamine reagent is employed. The lower reactivity of hydroxymethylfurfural in the standard Dische test indicates that a second role of chloride is to accelerate the reaction between the furfural and diphenylamine. The low reactivity of glucose, the slow kinetics of its reaction, and the close identity of the absorption spectrum of its reaction product with that of fructose raise some question as to whether with glucose the reactive component may be fructose.

\section{SUMMARY}

The sensitivity of the Dische test (diphenylamine) for DNA is reduced by the presence of chloride ions, which cause formation of a new reaction product whose absorption maximum is at lower wavelength, and also a reduction in the total chromogenic potential. Additionally, the reaction with other sugars (particularly fructose) is intensified by chlorides reducing the specificity of the reaction for DNA.

\section{REFERENCES}

1. Dische, Z., in "The Nucleic Acids" (Chargaff, E., and Davidson, J. N., eds.). Academic Press, New York, 1955.

2. Dische, Z., Mikrochem. 7, 33 (1929).

3. Dische, Z., Mikrochem. 8, 4 (1930).

4. Sneld, F. D., ANd Snell, C. T., "Colorimetric Methods of Analysis," 3rd Fd.. Vol. 3, p. 312. Van Nostrand, New York, 1953.

5. Segovia, Z. M. M., Sokol, F., Graves, I. L., and Ackermann, W. W.. Biochem. Biophys. Acta 95, 329 (1965). 